\title{
El entrenamiento de becarios se asocia a una gran carga de trabajo de guardia, estrés físico y deprivación de sueño
}

\section{Objetivo}

Evaluar las condiciones de trabajo, el cansancio y el estrés físico en los becarios.

\section{Diseño}

Estudio observacional prospectivo*.

\section{Lugar}

Ontario, Canadá. Unidad de terapia intensiva pediátrica del "Hospital for Sick Children" de Toronto (afiliado a la Universidad).

\section{Sujetos}

Participaron 11 becarios avanzados, evaluados durante un período de 6 meses. Los becarios trabajaron bajo las normas de la Asociación Profesional de Internos y Residentes de Ontario.

\section{Medición de los resultados principales}

1) Evaluación de condiciones de trabajo: a- Número total de horas de trabajo asignadas a los becarios. b- Número total de pacientes y su gravedad (ventilación asistida, oxigenación por membrana extracorpórea, hemodiálsis y oscilación de alta frecuencia).

c- Registro Prospectivo de los becarios de cada procedimiento ejecutado o supervisado, número de pacientes que trasportaron fuera de la unidad, número de veces que los llamaron por altavoces y la ocurrencia de paro cardiorrespiratorio y muerte en pacientes que ellos asistían. d- Al finalizar cada guardia, el participante evaluó cuan atareada y estresada había sido la jornada empleando una escala numérica de 1 (poco) a 7 (mucho). e- Impacto del sistema de apoyo: relación enfermeros/pacientes; número de médicos de staff presentes y las horas de sus partidas; comunicación subsiguiente entre becario y staff; ocasiones en que el staff regresó a la unidad luego de haberse ido.

2) Evaluación de de estrés fisiológico: a- Distancia caminada en cada guardia: medidor deportivo común. b- Duración de sus recreos y el tiempo total de sueño. c- Se hicieron análisis de orina al final de 33 guardias. d- Holter cardíaco en 9 guardias en 6 participantes.

\section{Resultados principales}

Horas medias semanales asignadas a cada becario: 69 . Estuvieron de guardia: 5-7 días cada 28. El promedio de pacientes internados al iniciar la guardia fue de 22 (56 \% recibió ventilación asistida y fueron admitidos cada guardia una media de 5.2 chicos). Recibieron 41 llamados por altavoces, (65\% entre 6 PM y fin de guardia). Manejaron una resucitación por cada 7 guardias y murió uno cada 12 niños. En promedio cada guardia: los participantes caminaron unos $6,3 \mathrm{Km}$., destinaron 70 minutos para comidas, y durmieron 1,9 hs. Densidad urinaria media: 1.02 y Holter: 2 casos de ectopias significativas; todos evidenciaron predominio simpático.

\section{Conclusión}

Las pautas de trabajo establecidas por Canadá y propuestas por EE.UU, exponen a los becarios a una significativa carga de trabajo de guardia, así como a estrés físico y deprivación de sueño.

Fuente de financiamiento: sin financiamiento externo.

\section{Comentario}

No sorprende el hecho de que trabajar 60-80 hs. semanales en un sistema de sobrecarga de tareas derive en deprivación de sueño y sus consecuencias: deterioro de la salud del médico, su desempeño y la seguridad del paciente que es asistido bajo esas condiciones de cansancio.

En ciertas industrias como la del transporte, ante un accidente, es común realizar investigaciones para evaluar el esquema de trabajo /descanso de los conductores involucrados. Es probable, que si se realizaran estudios similares ante un error en la atención médica, se encontrarían frecuentemente altos niveles de fatiga en el profesional que intervino. Este estudio, deja de lado algunas variables de peso: los efectos de la comunicación verbal y de la interacción entre el profesional y el sistema paciente-familia (estrés de rol). Tema de suma importancia, dado que la formación académica suele incluir solamente el entrenamiento en habilidades técnicas, dejando las competencias comunicacionales en un nivel amateur. Ello conduce a un disbalance demanda laboral - recurso de afrontamiento, otra fuente de estrés. ${ }^{2}$ Tampoco ha tenido en cuenta el "clima laboral", pues ha considerado solo el componente estructural del sistema de apoyo. ${ }^{3}$

De todos modos, lo interesante de este estudio es que aporta evi- dencia de que el esquema de capacitación para becarios adoptado en dicho Hospital Escuela, aún cumpliendo las reglas sugeridas por los organismos de regulación de su país, proveen de un esquema de trabajo que altera negativamente la fisiología de los participantes.

\section{Conclusiones del comentador}

Cuidar el estrés del médico no solo es necesario por la salud de él mismo sino por la de los pacientes a los que él asiste. Un abordaje integral es necesario. Podría emplearse el modelo de Practica Integral que propone Wilber:4,5 actuar desde cuatro dimensiones en forma simultánea: 1- Interior individual (dimensión psicológica): el médico puede entrenarse en relajación y catarsis emocional. 2Exterior individual (dimensión conductual): entrenamiento físico y alimentación saludable. 3- Exterior colectivo (social): generar esquemas de trabajo que permitan un descanso razonable y entrenamiento en habilidades comunicacionales 4- Interior colectivo (cultural): generar una cultura compartida que valore el descanso adecuado.

\section{Dr. Daniel Sidelski [ Profesor Adjunto de la materia Psicopatología II en la Universidad de Flores. ]}

Sidelski D. El entrenamiento de becarios se asocia a una gran carga de trabajo de guardia, estrés físico y deprivación de sueño. Evid. actual. pract. ambul. 2005;8:45. Comentado de: Fellowship training, workload, fatigue and physical stress: a prospective observational study. Parshuram S, Dhanani S, Kirsh J. CMAJ. 2004;170(6):965-70. PMID: 15023923.

\section{Referencias}

1. Mitler MM, Dement WC, Dinges DF, Sleep medicine, public policy, and public health. In: Kryger MH, Roth T, Dement WC, editors. Principles and practice of sleep medicine, 3rd ed. Philadelphia: WB Saunders; 2000. p. 580-8.

2. Rodríguez Marín J. Psicologìa Social de la Salud Ed Síntesis 2001 cap 7, 8 y 9 pag 119-160.

3. Peiro J. M. y Prieto F. Tratado de Psicologìa del Trabajo, Ed Síntesis 1996 Vol 1 cap 2 pag 37-90.

4. Wilber K. Una teoría de todo. Ed Kairos 2000 Cap 3 pag 58- 93.

5. Wilber K. Una visión integral de la psicología. Ed Alamah. 2000 